\title{
How Brands in India connected with the audience amid Covid-19
}

\author{
Manjot Kaur Shah ${ }^{1}$, Sachin Tomer ${ }^{2}$ \\ 1. Assistant Professor, Mata Sundri College, University of Delhi \\ ${ }^{2}$. Assistant Professor, Ramanujan College, University of Delhi \\ DOI: 10.29322/IJSRP.10.08.2020.p10414 \\ http://dx.doi.org/10.29322/IJSRP.10.08.2020.p10414
}

\begin{abstract}
The companies spent a huge amount in promoting their products to the public. Even at the times when the market came to a standstill owing to nation-wide lockdown to fight with Coronavirus, the companies continued to promote their products amid Covid-19. Some companies continued with their old advertisements while others made changes in their advertisement to include the coronavirus aspect in their promotion. In this paper, we have analysed the way the companies have responded in their promotion to fight with this unknown virus either by way of sending messages, creating awareness or the way their product would help people in fighting with this virus. We have taken into consideration the television advertisement and the promotion and hashtags used on their Instagram page. The companies selected are either Indian companies or companies whose products are available in India.
\end{abstract}

Index Terms- brands, advertisement, hashtags, coronavirus, covid-19.

\section{INTRODUCTION}

$\mathrm{C}$ ovid-19 has become a pandemic that has affected the entire world. There was not much knowledge and information about this virus before December 2019. It was only after the virus that was first detected in Wuhan, China in 2019 that all the nations came into action to fight with this unknown virus. Coronaviruses cause illness in animals and humans. It causes respiratory infections in humans ranging from common cold to more severe outcomes. This virus can spread through droplets from the nose or mouth which are expelled when a person carrying the virus sneezes, cough or speaks. And that is the reason that the virus travels and spreads very fast. There were a total of $13,824,739$ confirmed cases worldwide and 1,038,716 cases in India as per the WHO data as on $18^{\text {th }}$ July, 2020. India was under lockdown since $25^{\text {th }}$ March, 2020 and this lockdown continued till 30th May, 2020. The government eased most of the restrictions of lockdown and rolled out 'Unlock 1.0' from 1st June, 2020. There were still restrictions on shopping malls, movie halls etc.

As pointed out by Singh \& Singh (2020)

There is a big shift in the world economic market and the share market has witnessed crashes day by day. Factories, Restaurants, Pubs, Markets, Flights, Super Markets, Malls, Universities and Colleges etc. were shut down. Fear of corona virus has limited the movement of the individuals. People were not even going to buy the daily essentials and these all were somewhere impacting the economy of the world as a whole. (p.170-171)

Social media is a very powerful tool in the hands of marketers. Social media is considered to be a more trustworthy source as compared to the traditional sources of promotion like television advertisements (Foux, 2006).

\section{THE ADVERTISING INDUSTRY}

The malls, the market places and shops selling nonessential products were prohibited to operate during lockdown. The companies and retailers especially the small retailers and businesses were the worst hit during this time. Most of the companies despite the loss in sale continued to promote their products. The impact of coronavirus was also seen on television advertisements. As per the report published in Financial express, as per industry estimates, the expected decline in expenditure on television expenditure would be somewhere between $50-55 \%$ or Rs 3,750 Crore- 4,125 Crores between April 2020-June 2020 (Mahendra,2020). According to another data released by TAM AdEX as mentioned in the online issue BrandEquity.com from The Economics Times, the advertisement that revolves around the coronavirus has increased and there were around 41,000 minutes advertisement between $22^{\text {nd }}$ March, 2020-28 ${ }^{\text {th }}$ March,2020 (Malvania,2020). There has been a decrease in commercial advertisement and a huge increase in social advertisement.

\section{HOW THE BRANDS IN INDIA RESPONDED TO COVID-19 IN THEIR TELEVISION ADVERTISEMENT.}

Though there had been a decrease in the television advertisement owing to Covid-19, there were brands who took this opportunity to stay connected with customers during this tough time. The television advertisements in India were viewed in order to analyse the response of brands to coronavirus and what changes they had made in their advertisements or taglines. One of the advertisements by Dettol Soap where they asked the public to wash their hands with any soap to protect from germs was very apt at this time. They not only promoted their product but also conveyed the message as to why washing hands is important to protect ourselves. They also spread this message through their advertisement to promote Dettol Handwash. Dettol also came up with a new advertisement featuring famous celebrities who 
prepared their part of advertisement from their place following the lockdown guidelines. The celebrities were seen washing their hands and spreading the message to wash hands for 20 seconds. Another popular soap brand, Lifebuoy added the term "virus fighter" with their brand name and urged people to defeat the virus. The brand Savlon also came up with an advertisement to create awareness about Coronavirus. Yet another brand Lux , which is popular for beauty soap came up with a short advertisement where the Lux soap was also being used for washing hands and it changed its tagline to "Stay Protected, Stay Beautiful". It did not mention the virus directly in the advertisement. Still the message to stay protected was sent across. Lux also continued with other advertisements without making any changes.

Lizol came up with the advertisement issued in public interest to educate the people about the importance of disinfecting the regularly touched surface at home to fight against coronavirus. They requested the public to disinfect using any disinfectant. Lizol did not promote their disinfectant in the advertisement except that at the end of advertisement the name of the brand was reflected. Even the disinfectant bottle that was used in the advertisement did not mention the brand name but one could make out from the shape and color of the bottle that the disinfectant is Lizol. They used celebrities like Kareena Kapoor and Saif Ali Khan for spreading this message.

Surf Excel is known for their heart-warming advertisements. They came up with advertisements where in a way they urged people to stay home. This advertisement was directed at children who have been stuck at home owing to the lockdown. It also had a positive message that all this will only be for a short period of time and then life will get back to normal. They also used the hashtag that the stains will stay at home since most of the people will be at home during the lockdown. This video was also uploaded on YouTube and had more than 55 lakhs views by June, 2020.

After some relaxation in the lockdown regulations, the popular Pizza brand, Domino's came up with an advertisement to spread a message about the contactless delivery that the brand is making. They also highlighted the rules that they follow to ensure safety measures. They came up with the tagline "Great Taste. Delivered Safe". These kinds of advertisements play a very important role in winning the trust and confidence of the customers who fear placing orders due to safety concerns.

The mention of Coronavirus in advertisement was not only done by brands dealing in personal care products but also by brands like lenskart.com where people who broke their eyeglasses during lockdown were able to get glasses from lenskart.com. Another brand, India Gate, who deal with rice came up with a new advertisement with reference to covid-19 and lockdown. Horlicks also launched a new advertisement amid covid. Some brands were quick enough to make changes in their advertisement and came up with new advertisements with mention of coronavirus. While others continued with their already existing advertisement.

\section{Use Of Instagram Hashtags to Stay Connected With Audience During Covid Times}

Most of the brands have official pages on Instagram. For our study we visited the Instagram handle of Indian companies and analysed their posts after the coronavirus forced the nation to lockdown. Most of the brands selected had verified Instagram handle. Only Dettol India did not have verified Instagram pages. Our study would only focus on the hashtags used by brands in their posts.

\section{Savlon.India (112 posts, 6643 followers)}

Savlon came up with \#ChainOfProtection where people including celebrities from the film industry and their children were found using sanitizers to clean their hands. This chain of protection aims to break the chain of infection. They also highlighted the importance of social distancing with the quote that "Sometimes the only way to stand together is to stand apart". Another popular hashtag used by Savlon was \#GetActiveWithSavlon, where people were asked to create fun and engaging activities for children and also teach them the importance of hand hygiene. They also came with \#SurakshaAapkeHaathMein meaning that protection is in your own hand again highlighting the importance of hand washing and sanitizing hands to fight with the virus.

\section{Dettol.India (68 posts, 4903 followers)}

Dettol used hashtags like \#apnisurakshaapnehaath meaning that your protection is in your own hand. This was similar to the hashtag used by Savlon. They also came up with \#handwashchallenge to encourage hand washing habits among the public and to make hand washing look cool.

\section{Lizol India (50 posts. 712 followers)}

With only 313 followers, Lizol India page became active post Covid-19. There was an increase in the number of followers and they also had verified Instagram handle. Their popular hashtag was \#DisinfectToProtect where the importance of disinfecting was highlighted.

\section{Parachute Advansed (184 posts, 5096 followers)}

They came up with \#BondOverAChampi where families were seen applying oils to help them de-stress and relax while they stay at home. Another hashtag that was used was \#MoreStrenghtToYou which was dedicated to the multiple roles the women had to play owing to lockdown.

\section{Harpic India (119 posts, 972 followers)}

They continued its mission to save water by using hashtags \#staysafe \#savewater by conveying the importance of hygiene and washing hands but also encouraging them to save water while doing so.

\section{Samsung India (3070 posts, $2.6 \mathrm{M}$ followers)}

They have been very active on Instagram following the lockdown. They used hashtag \#GetThroughThisTogether where they urged people to pre-book their orders from the comfort and safety of their homes and also gave some exciting offers so that customers place orders amid lockdown. They also came up with \#MakeMemoriesAgain where the followers were asked to dig out their old picture with family, recreate it and also give a chance to get featured. This was very interesting and they got a really good response from the public. They also came up with online service appointments. As a mark of respect they also thanked health care workers on International Nurse Day. There was so much focus on 
handwash that they came up with the Handwash App on Galaxy Smart Watch where the reminder for hand wash, wash time counter and daily hand wash trend tracker was built to track the hand wash habit of the user. They urged and thanked people again and again for staying at home. They also posted about their contribution to the PM Cares Fund. Mobile phones can be another source of passing the virus. They also taught people how the mobile phone can be sanitized. Another important initiative was that of extending the warranty for all the customers whose warranty was expiring between $20^{\text {th }}$ March, 2020 and $30^{\text {th }}$ March, 2020.

\section{LG India (1153 posts, $50.9 \mathrm{~K}$ followers)}

The hashtag used by them was \#StayHomeStayEntertained, \#LGCaresForYou, \#MultiTaskFromHome. They also asked their followers to stay inside their homes and follow the lockdown guidelines. They also extended the warranty period for the customers. Posting about the contribution to society was common for all. They contributed meals to the underprivileged during the lockdown. They extended their tagline "Life is Good" to tell people that life is good when you have more me time, more productivity, more family time and more relaxation. They also taught the importance of social distancing.

\section{Ponds India (2545, 184K followers)}

They used hashtag \#LoseTheMakeupNotTheGlow since during the lockdown most of the women were at home and they did not go out for work, socializing etc. They also used hashtags such as \#StayIn \#StaySafe \#SelfCare.

\section{Suzuki Motorcycle India (1754 posts, 253K followers)}

They were continuing with their original promotion posts till $3^{\text {rd }}$ of April. 2020. On $4^{\text {th }}$ April, 2020 they came up with a post where due to lockdown they extended the warranty expiring between $15^{\text {th }}$ March, 2020 and $30^{\text {th }}$ April, 2020 to $30^{\text {th }}$ June, 2020. They used hashtags \#Stayhome \#Stay safe which was used by most of the companies. They also came up with \#ARideToRemember where the followers were asked to share their throwback stories from the road. They also gave maintenance tips for two wheelers to their customers. They also used \#StayInStaySafe. They also replaced different hand movements while riding bikes with safety measures that need to be taken. In one of the posts a person was seen opening the dustbin it was mentioned on the image that "Pressing the brake pedal be like". In another post the twist in the wrist was shown as wringing the clothes. Suzuki Motorcycle became very active on Instagram during Covid time.

\section{Hero MotoCorp (1507 posts, $108 \mathrm{~K}$ followers)}

They extended the warranty period till $30^{\text {th }}$ June, 2020. They gave tips to store bikes when not in use. They used hashtags like \#Stayhomestaysafe. They also posted about their contribution to society in the form of distribution of masks and hand sanitizers which were produced in their manufacturing plants. They requested people to stay indoors and said that staying indoor was the most heroic thing that they can do.

\section{Toyota India (701 posts, $224 \mathrm{~K}$ followers)}

They have been active on Instagram since this lockdown was introduced. Their first post came on $21^{\text {st }}$ March, 2020 ahead of one day lockdown in India on $22^{\text {nd }}$ March, 2020. They used hashtag \#ToyotaWithIndia signifying that the company is with India during its fight with Covid. They urged people not to go out and stay back at home as safety can't take a backseat and it is important for all to stay safe. They showcased the car seats but requested people to enjoy the interiors of their house rather than Toyota cars. They were very innovative in staying connected with the followers. They also asked people to be responsible as luxury can wait but responsibility cannot. They also make use of the car seats to urge people to take responsibility to flatten the curve of Covid. So the curve of their car seat was compared with the curve of Covid. They also extended the warranty period by two months. When the lockdown gave some relaxations, they used \#WeAreSafe to ensure their customers that their safety would be taken care of.

\section{Maruti Suzuki (257 posts, 28.7K followers)}

They urged people not to drive during lockdown and stay inside. They used hashtags like \#FlattenTheCurve, \#GearUpForTomorrow, \#SelfIsolation, \#WorkFromHome, \#IndiaFightsCorona and \#BreakTheChain. They gave tips for car care. They also asked followers to share their throwback pictures. They also used \#SocialResponsibilty to ensure public safety and their contribution in the form of distribution of 2 million face masks.

\section{Hyundai India (2345 posts, 863K followers)}

Hyundai was very active on Instagram. They asked followers to stay safe and that the key to safety is to stay at home. They used hashtags like \#FlattenTheCurve, \#HyundaiCares, \#StayHome, \#StaySafe, \#WePledgeToBeSafe, \#ProgressForHumanity. This company sells cars but urges people not to drive. They asked people to stop the wheels to race ahead. They also used \#0KMPH. They were also very innovative in their promotion during the lockdown. They used images of engine start and stop buttons and asked people to start distancing and stop the spread of coronavirus. They also asked people to take foot off the pedal and to respect the lockdown. They also posted about their contribution to the CM Relief Fund and distribution of PPE kits and dry rations. They depicted very nicely that the safest destination during lockdown is house and one should stay inside. The brands were really innovative in their promotion both on television and using social media like Instagram. They also highlighted their contribution to society during these tough times. "This pandemic offers great opportunities for firms to actively engage in various CSR initiatives during the crisis, and potentially catalyse a new era of CSR development in the long run." ( He \& Harris, 2020, p. 20). Using social media for communicating CSR activities is highly recommended (Kesavan, Bernacchi, \& Mascarenhas, 2013) and when the entire world is going through a crisis this becomes even more important. The customers and public are interested in knowing how responsible the companies are. Social media is a trustworthy medium for CSR communication and it helps the companies in building relationships with customers and other stakeholders (Ali, JiménezZarco, \& Bicho, 2015). 
The word cloud of hashtags used is shown in the figure 1. The focus was on staying home and staying safe. The most commonly used words in hashtags were stay, home, safe, chain, India, break, curve, flatten, cares, corona, coronavirus, fights, safe, self, tomorrow. The main motive in using these hashtags were to highlight the importance of safety to fight with the virus. They also wanted to make a contribution to help flatten the curve.

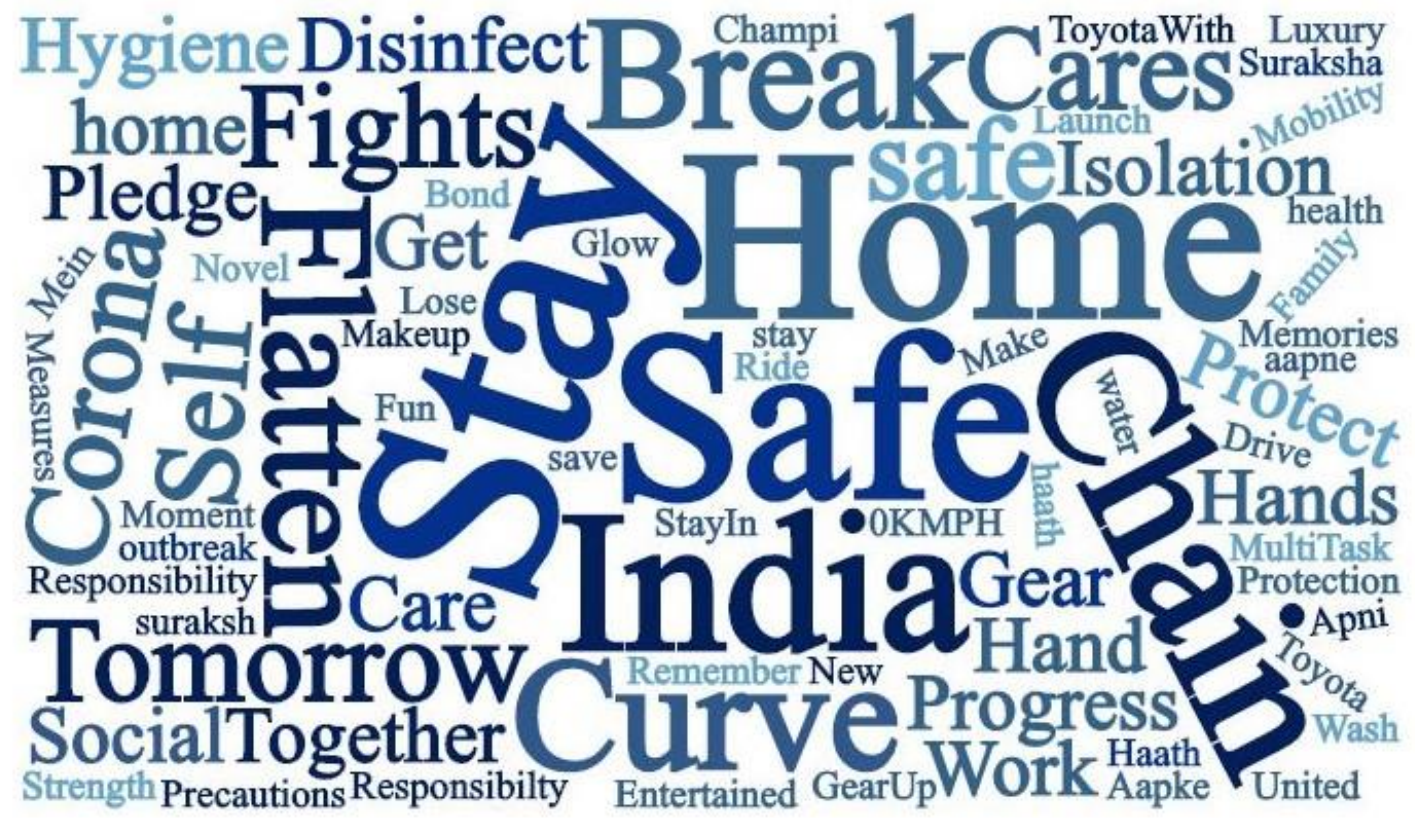

Figure 1: Word cloud of hashtags

\section{FINDINGS OF THE STUDY}

The brands were quick enough to respond to coronavirus and connect with the audience using various hashtags. The hashtags used revolved around covid-19. They also came up with various schemes like extending the warranty period that was expiring during the lockdown period. This scheme was very popularly used by the automobile and electronic industry. The brands were very creative in modifying their advertisement to include the corona aspect in their promotion. Not only personal care brands but also brands dealing in products which do not provide any kind of protection against coronavirus also came up with the promotion during this period. The marketers need to understand that even if there may be a decrease in the sales, staying in the minds of consumers is of utmost importance. Social media is one such platform where the brands can easily connect with the customers.

\section{REFERENCES}

[1] Ali, I., Jiménez-Zarco, A. I., \& Bicho, M. (2015). Using social media for CSR communication and engaging stakeholders. Corporate Social Responsibility in the Digital Age (Developments in Corporate Governance and Responsibility, 7, 165-185.
[2] Foux, G. (2006). Consumer-generated media: Get your customers involved. Brand Strategy, 8(202), 38-39.

[3] Kesavan, R., Bernacchi, M. D., \& Mascarenhas, O. A. (2013). Word of mouse: CSR communication and the social media. International Management Review, 9(1), 58-66.

[4] He, H., \& Harris, L. (2020). The Impact of Covid-19 Pandemic on Corporate Social Responsibility and Marketing Philosophy. Journal of Business Research.

[5] Mahendra, V (2020, March 31). Coronavirus Impact: Ad expenditure to decline by $50-55 \%$ on TV between April-June 2020. Financial Express, Retrieved from https://www.financialexpress.com/brandwagon/coronavirusimpact-ad-expenditure-to-decline-by-50-55-on-tv-between-april-june2020/1914445/

[6] Malvania, U. (2020, April 10). Coronavirus related ads on TV crossed 40,000 minutes in last week of March. Brand Equity.com, The Economics Times, Retrieved

from https://brandequity.economictimes.indiatimes.com/news/advertising/corona virus-related-ads-on-tv-crossed-40000-minutes-in-last-week-of$\operatorname{march} / 75075903$

[7] Singh, J., \& Singh, J. (2020). COVID-19 and its impact on society. Electronic Research Journal of Social Sciences and Humanities, 2.

\section{AUTHORS}

First Author - Manjot Kaur Shah, Assistant Professor, Mata Sundri College, University of Delhi

Second Author - Sachin Tomer, Assistant Professor, Ramanujan College, University of Delhi 
International Journal of Scientific and Research Publications, Volume 7, Issue 8, August 2017

ISSN 2250-3153

www.ijsrp.org 